\title{
A musicalização como ferramenta para o desenvolvimento de potencialidades na educação infantil
}

Simone Martins N. Borges

Licenciada em Música, UBM.

Pós graduada em Educação Musical, Centro Universitário Claretiano 


\section{Resumo}

Este trabalho busca investigar contribuições de aulas de Musicalização na vivência e desenvolvimento de potencialidade de educandos da Educação Infantil, através da observação de professoras regentes de turma. Traz reflexões sobre a Música e Musicalização, suas definições, funções, áreas de conhecimento, teor lúdico e aplicabilidade na Escola. A pesquisa bibliográfica e aporte teórico respaldam-se, além dos Referenciais Curriculares Nacionais de Educação Infantil - RCNEI, também nas contribuições de Cardoso e Mascarenhas (1973), Brito (2003), Penna (1990), Souza (2004), Jannibelli (1971), Chiarelli e Barreto (2005), e com pesquisa de campo qualitativa descritiva em forma de questionários. Nas considerações finais, elucida se houve desenvolvimento e quais foram identificados. Os apontamentos colhidos foram relacionados pela autora com as diretrizes para trabalho com Música no RCNEI. A investigação é relevante por trazer elementos para avaliação e reflexão, que podem contribuir para a práxis de outros professores, sejam de Música, Educação Infantil ou outros segmentos.

Palavras-chave: Música. Musicalização. Educação Infantil. Referencial Curricular Nacional de Educação Infantil - RCNEI.

\section{Abstract}

This work seeks to investigate the contribution of Musicalization classes in the experience and development of potentialities of children's education through the observation of class teachers. It brings reflections on Music and Musicalization, its definitions, functions, areas of knowledge, as well as ludic content and applicability in the School. The bibliography and theoretical support are supported, in addition to the National Curriculum Infantile Education - NCFIE, with the contributions of Cardoso and Mascarenhas (1973), Brito (2003), Penna (1990), Souza (2004), Jannibelli (1971), Chiarelli and Barreto (2005), and with descreptive qualitative field research in the form of questionaries. In the final considerations, it is clarified if there was progress and which was identified. The notes collected were related by the author with the guidelines for work with Music in the NCFIE. The investigation is relevant beacause it brings elements for evaluation and reflection, which can contribute to praxis to other teachers, either on Music, Early Childhood Education or other segments.

Keywords: Music. Musicalization. Child education. National Curricular Framework of Infantile Education - RCNEI. 


\section{Introdução}

A Música está presente nas manifestações sociais e pessoais do ser humano. Segundo Penna (1990, p. 20) “[...] sendo uma linguagem artística, organizada e estruturada culturalmente, a música, juntamente com o código de sua construção, é um fato histórico e social”. Green (apud SOUZA 2004, p. 08) explica que “[...] se o sociólogo pretender estudar o fato musical, ele deverá considerar a música como uma comunicação sensorial, simbólica e afetiva que pode, muitas vezes, estar subjacente à nossa consciência". Jannibelli (1971, p. 23) afirma que "A musicalização do indivíduo nos grupos sociais, mesmo os mais primitivos, se processa desde o momento em que nasce". De acordo com a autora, a linguagem falada, apesar de parecer uma atitude ou expressão inata, é também gradualmente adquirida, assim como o processo de Musicalização. Vivemos cercados de sons, produzidos pelas pessoas ou pela natureza. Após nascer, o ser humano "mergulha" num ambiente de sons, onde muitos são musicais. Eles são importantes por permitir que nos comuniquemos e possamos expressar emoções e ideias.

O RCNEI - Referencial Curricular Nacional de Educação Infantil (BRASIL, 1998, p. 47) afirma que:

[...] existe música para adormecer, música para dançar, para chorar os mortos, para conclamar o povo a lutar, o que remonta a sua função ritualística. Presente na vida diária de alguns povos, ainda hoje é tocada e dançada por todos, seguindo costumes que respeitam as festividades e os momentos próprios a cada manifestação musical. Nesses contextos, as crianças entram em contato com a cultura musical desde muito cedo e assim começam a aprender suas tradições musicais.

Nossas tradições musicais guardam heranças que atravessam séculos, sendo muitas vezes preservadas na transmissão oral.

De acordo com Penna (1990, p. 20)

A compreensão da Música, ou mesmo a sensibilidade a ela, tem por base um padrão culturalmente compartilhado: um código para a organização dos sons numa linguagem artística que, socialmente 
apreendido - pela vivência, pelo contato cotidiano, pela familiarização - embora também possa ser apreendido na escola.

Mesmo a Música nascendo de um contexto social e intercalando-se com outras atividades culturais que asseguram a continuidade de nossa herança cultural, ela também deve ser vista como forma de comunicação possível entre indivíduos que não sejam do mesmo grupo. Dessa forma, ela pode agregar indivíduos de grupos diferentes em torno de uma mesma produção ou linguagem musical.

Souza cita o estudo de Müller (2000, p. 117), realizado com crianças e adolescentes em Porto Alegre, em que relatam encontrar uma coesão no gênero musical do Rap, se reconhecendo como integrantes do movimento hip hop, sentindo-se legitimados e identificando-se com o gênero também por uma questão étnica. Ao compreender que esses grupos sentem a Música como forma de linguagem, é possível entender que, para eles, essa relação seja cheia de significados, ocorrendo independentemente da origem de cada indivíduo. $\mathrm{O}$ fato de pertencerem a um grupo faz com que se sintam mais "confiantes".

\section{Fundamentação Teórica}

\section{DEFINIÇÕES E APLICABILIDADE ENTRE MÚSICA E MUSICALIZAÇÃO}

Diversas são as maneiras que os indivíduos percebem e sentem a Música, atribuindo a ela significados subjetivos. $\mathrm{Na}$ contemporaneidade, seu conceito está ampliado, e todo som passa a ser qualificado como musical, até o que nossos ouvidos não captam.

Existem diversas definições para Música, tornando-se muito difícil encontrar um conceito que possa englobar todos os seus significados, até porque ela está sempre evoluindo. Para Cardoso e Mascarenhas (1973, p. 08), "É a arte de combinar os sons.", porém, esses autores observam que esta é uma definição clássica, pois hoje em dia, com efeitos modernos, sons e inovações do ritmo e harmonia, novos elementos têm sido acrescentados. Já Brito (2003, p. 26) discorda que Música possa ser definida como conjunto ou arte de combinar sons. Para ela, são definições inadequadas já que “[...] 
nem toda música é constituída por melodia e harmonia." Chiarelli (HOUAISS apud Bréscia, 2003, p. 25) conceitua a música como “[...] combinação harmoniosa e expressiva dos sons e arte de se exprimir por meio de sons, seguindo regras variáveis conforme a época, a civilização etc.”.

No RCNEI (BRASIL, 1998, p. 45) encontramos a seguinte afirmação: "A música é a linguagem que se traduz em formas sonoras capazes de expressar e comunicar sensações, sentimentos e pensamentos, por meio da organização e relacionamento expressivo entre som e o silêncio".

Brito (2003, p. 17) define que som "[...] é tudo que soa! Tudo que o ouvido percebe sob a forma de movimentos vibratórios.", e que os sons dos quais estamos cercados são expressões da vida e todos os elementos que a integram traduzindo sonoramente sua presença.

$\mathrm{Na}$ contemporaneidade, as formas de fazer música têm explorado diversas possibilidades como: instrumentos musicais feitos de material reciclado, utilização de sons corporais, utilização da voz para reproduzir sons de instrumentos musicais. $\mathrm{Na}$ afirmação de Brito (2003, p. 26) "Música não é melodia, ritmo ou harmonia, ainda que esses elementos estejam muito presentes na produção musical com a qual nos relacionamos cotidianamente. Música é também melodia, ritmo, harmonia, dentre outras possibilidades de organização do material sonoro". Pessoalmente, a afirmação de Brito me faz refletir que ações musicais diversificadas, que promovam a criatividade, experimentação e improvisação, aliadas a qualidades do som e o valor do silêncio, ajudam o indivíduo a organizar e a se relacionar com o material sonoro que recebe.

Em muitas culturas, a Música está intimamente ligada à vida dos indivíduos, fazendo parte do seu cotidiano. Menuhim e Davis (apud PENNA, 1990, p. 19) ressaltam que "A música é a nossa mais antiga forma de expressão, mais antiga que a linguagem ou a arte [...]”. A linguagem Musical promove interação e comunicação social, sendo significativa sua presença no contexto educacional de modo geral.

Cage (apud BRITO, 2003, p. 27) considera que “[...] música não é só uma técnica de compor sons (e silêncios), mas um meio de refletir e de abrir a cabeça do ouvinte para o mundo". Das definições apresentadas, considero ser essa a mais abrangente, por não limitar a música a símbolos, regras e nomenclaturas, mas por possibilitar ao indivíduo estabelecer uma relação própria, em que ele possa atribuir à Música novos significados e representações. 
A Musicalização é o processo em que o indivíduo se torna sensível aos sons, ritmos, músicas, e aprende a se relacionar com todo esse material sonoro de forma lúdica e livre de rigores, sentindo-a de forma subjetiva.

Para Bréscia (apud CHIARELLI, 2005, p. 03) “[...] a musicalização é um processo de construção do conhecimento, que tem como objetivo despertar e desenvolver o gosto musical”. Penna (1990, p. 43) a define “[...] como processo educacional orientado, que visa desenvolver os instrumentos de percepção, expressão e pensamento necessários à decodificação da linguagem musical, como forma de promover, em todos os alunos, a competência artística." Ainda, a mesma autora discorre que o processo de Musicalização é fazer o indivíduo sensibilizar-se com a música, de modo que reaja, mova-se internamente com ela. Em termos específicos, ao tornar o indivíduo sensível e receptivo ao fenômeno sonoro, promove nele, ao mesmo tempo, respostas de índole musical. Na prática, funciona como a "pré-escola" da música, em que através da realização de atividades intuitivas, cria-se um estado mental intelectual favorável à aquisição de conhecimentos musicais.

O processo musical acontece através da aplicação de atividades lúdicas, que visam aperfeiçoar e desenvolver a coordenação motora, socialização, afetividade, imaginação e expressividade. O lúdico é desenvolvido através de jogos e brincadeiras que estimulam o desenvolvimento da expressão Musical. Os jogos e brincadeiras, necessariamente, não exigem complexidade e podem, inclusive, ser adaptados para as possibilidades dos alunos, permitindo trabalhar regras, expressão corporal e ampliação cultural. Segundo Brito (2003, p. 42) "Aproximando-se da etapa do jogo com regras, a música passa a ser também um vasto domínio para a sistematização e a organização do conhecimento". Ainda a mesma autora descreve a criança como um ser brincante, sendo a brincadeira sua forma de se relacionar com o mundo e fazer Música.

O RCNEI (BRASIL, 1998, p. 48) afirma que:

[...] o contato intuitivo e espontâneo com a expressão musical desde os primeiros anos de vida é importante ponto de partida para o processo de Musicalização. Ouvir música, aprender uma canção, brincar de roda, realizar brinquedos rítmicos, jogos de mãos etc. são atividades que despertam, estimulam e desenvolvem o gosto pela atividade 
BORGES, S. M. N. A musicalização como ferramenta para o desenvolvimento de potencialidades na educação infantil. $R$. Cientifica UBM - Barra Mansa (RJ), ano XXIV, v. 21, n. 40, 1. Sem. 2019. p. 40-56.

ISSN 1516-4071

musical, além de atenderem a necessidades de expressão que passam pela esfera afetiva, estética e cognitiva.

A Musicalização é iniciada no lar, onde a criança percebe os sons do cotidiano, de seus familiares, através de rádio, TV, etc. Na escola, com esse processo já iniciado, deve ser direcionado para um aproveitamento na Musicalização, para criar o gosto e o vínculo entre crianças e Música.

\section{MÚSICA NA EDUCAÇÃO INFANTIL}

A prática musical em espaços formais, na maioria das vezes, apoia-se num fazer mecânico e repetitivo, como algo estático e estabelecido. O RCNEI (BRASIL, 1998, p. 47) afirma que:

[...] vem, ao longo de sua história, atendendo a vários objetivos, alguns dos quais alheios às questões próprias dessa linguagem. Tem sido, em muitas coisas, suporte pra atender a vários propósitos como a formação de hábitos, atitudes e comportamentos: lavar as mãos antes do lanche, escovar os dentes...à realização de comemorações relativos ao Calendário de eventos do ano letivo, simbolizados no dia da árvore, dia do soldado, dia das mães etc.

Brito (2003) concorda que essa aplicação vem sendo feita para alcançar objetivos “considerados” adequados à instrução e formação infantis, e esclarece que a canção também é usada como condicionamento de rotina, disciplina, e, quase sempre, acompanhada de gestos e movimentos automatizados. A mesma autora afirma que os educadores em geral, excluem a criação em prol da reprodução. Mesmo na contemporaneidade, com os conceitos redimensionados e influenciados por novas pesquisas pedagógicas, detecta-se defasagem entre o trabalho realizado na área musical e nas demais áreas de conhecimento.

$\mathrm{Na}$ Educação Infantil é comum o uso de bandinhas rítmicas para complementar o processo de Musicalização, pois instrumentos atraem a atenção dos alunos, além de 
BORGES, S. M. N. A musicalização como ferramenta para o desenvolvimento de potencialidades na educação infantil. $R$. Cientifica UBM - Barra Mansa (RJ), ano XXIV, v. 21, n. 40, 1. Sem. 2019. p. 40-56.

ISSN 1516-4071

servirem de ferramenta para a produção sonora. Jannibelli (1971, p. 152) remonta a origem dessa prática às primeiras escolas maternais, como forma das Mestras (chamadas Jardineiras) "ocuparem" as crianças que estavam sob seus cuidados. A mesma autora informa que nas classes maternais das irmãs Agazzi ${ }^{1}$, as Mestras começaram a prática de aliar canto, jogos de recreação e marcação de ritmo com passos, brinquedos e instrumentos. Gradativamente outras escolas e educadores aplicaram esses mesmos processos, com o acréscimo de outros instrumentos.

$\mathrm{Na}$ contemporaneidade, o RCNEI (BRASIL, 1998, p. 47) observa que apesar da bandinha rítmica contribuir nos desenvolvimentos motor, rítmico e auditivo, possui pouca qualidade sonora, pelo fato dos instrumentos geralmente serem confeccionados com material inadequado. Assim sendo, sua utilização "[...] reforça o aspecto mecânico, deixando pouco ou nenhum espaço às atividades de criação e às questões ligadas a percepção [...]”. Brito (2003, p. 67) ressalta que apesar dos instrumentos da bandinha serem confeccionados em dimensões adequadas aos pequenos, muitas vezes há descuido em relação à qualidade do som, tornando o aspecto visual mais importante que o sonoro.

A importância da construção de instrumentos musicais e objetos sonoros é considerada por Brito essencial, para que os alunos entendam os elementos referentes à produção do som, suas qualidades e demais peculiaridades. Nas palavras da autora: "As crianças se relacionam de modo mais íntimo e integrado com a música quando também produzem os objetos sonoros, utilizados para fazer música [...]", enfatizando que a produção dessas peças não supre a necessidade de contato com instrumentos convencionais, sejam eles industrializados ou de confecção artesanal.

Segundo o RCNEI (BRASIL, 1998, p. 57) "O fazer musical é uma forma de comunicação e expressão [...]”. Brito (2003, p. 57) considera “[...] fazer musical como o contato entre a realização acústica de um enunciado musical e seu receptor [...]”. Ambos concordam que o fazer musical acontece por meio da improvisação, da composição e da interpretação. Esses conceitos estão descritos no RCNEI (BRASIL, 1998, p. 57) como:

- Improvisação: "Improvisar é criar instantaneamente, orientando-se por alguns critérios pré-definidos, mas com grande margem a realizações aleatórias, não determinadas.”

\footnotetext{
${ }^{1}$ De acordo com Kishimoto e Santos, as irmãs Rosa e Carolina Agazzi propuseram em Mompiano, Itália, em 1894, um método diferenciado e inovador para a Escola Infantil, utilizando-se principalmente de material não pré-ordenado,não científico e ocasional, que era definido como um bando de bugigangas sem patente.
} 
BORGES, S. M. N. A musicalização como ferramenta para o desenvolvimento de potencialidades na educação infantil. $R$. Cientifica UBM - Barra Mansa (RJ), ano XXIV, v. 21, n. 40, 1. Sem. 2019. p. 40-56.

- Composição: “Compor é criar a partir de estruturas fixas e determinadas.”

- Interpretação: “[...] interpretar é executar uma composição contando com a participação expressiva do intérprete."

Brito (2003, p.58) aponta que no cotidiano das creches e pré-escolas, a linguagem musical deve abranger as seguintes atividades: trabalho vocal; interpretação e criação de canções; brinquedos cantados e rítmicos; jogos que reúnem som, movimento e dança; jogos de improvisação; sonorização de histórias; elaboração e execução de arranjos (vocais e instrumentais); invenções musicais (vocais e instrumentais); construção de instrumentos e objetos sonoros; registro e notação; escuta sonora e musical; escuta atenta, apreciação musical; reflexões sobre a produção e a escuta.

\section{SOBRE ÂMBITOS E EIXOS NO RCNEI E OS OBJETIVOS LIGADOS À MUSICALIZAÇÃO}

Âmbitos são domínios ou campos de ação que dão visibilidade aos eixos de trabalho educativo para que o professor possa organizar sua prática e refletir sobre a abrangência das experiências que propicia às crianças. O RCNEI define dois âmbitos de experiências: Formação Pessoal e Social e Conhecimento de Mundo.

Formação Pessoal e Social refere-se às experiências que favorecem, prioritariamente, a construção do sujeito. Está organizado de forma a explicitar as complexas questões que envolvem o desenvolvimento de capacidades de natureza global e afetiva das crianças, seus esquemas simbólicos de interação com os outros e com o meio, assim como a relação consigo mesmas. $\mathrm{O}$ trabalho com este âmbito pretende que as instituições possam oferecer condições para que as crianças aprendam a conviver, a ser e a estar com os outros e consigo mesmas em uma atitude básica de aceitação, de respeito e de confiança. Este âmbito abarca um eixo de trabalho denominado Identidade e Autonomia.

O âmbito de Conhecimento de Mundo refere-se à construção das diferentes linguagens construídas pelas crianças, e às relações que estabelecem com os objetos de conhecimento. Este âmbito traz uma ênfase na relação das crianças com alguns aspectos da cultura. A cultura é aqui entendida de forma ampla e plural, como o conjunto de códigos e produções simbólicas, científicas e sociais da humanidade, construída ao longo 
BORGES, S. M. N. A musicalização como ferramenta para o desenvolvimento de potencialidades na educação infantil. $R$. Cientifica UBM - Barra Mansa (RJ), ano XXIV, v. 21, n. 40, 1. Sem. 2019. p. 40-56.

ISSN 1516-4071

das histórias dos diversos grupos, englobando múltiplos aspectos e em constante processo de reelaboração e ressignificação. Essa ideia de cultura transcende, mas engloba os interesses momentâneos, as tradições específicas e as convenções de grupos sociais particulares. O domínio progressivo das diferentes linguagens propicia a interação com os outros, e facilita a mediação com a cultura e os conhecimentos constituídos. Incide sobre aspectos essenciais do desenvolvimento e da aprendizagem e engloba instrumentos fundamentais para as crianças continuarem a aprender ao longo da vida.

Eixos, entre outras definições, podem ser entendidos como órgãos centrais de quaisquer movimentos reais ou figurados.

A Música e, consequentemente, a Musicalização, estão relacionadas ao âmbito de Conhecimento de Mundo. Este âmbito, segundo o gráfico do RCNEI (BRASIL, 1998 p. 85), contêm 6 eixos de trabalho. São eles: Música (já mencionado); Movimento; Artes Visuais; Linguagem oral e escrita; Natureza e Sociedade e Matemática. Estes eixos foram escolhidos pelo Referencial por constituírem uma parcela significativa da produção cultural humana, que amplia e enriquece as condições de inserção das crianças na sociedade.

Dentre os vários objetivos do RCNEI, selecionamos aqueles mais diretamente ligados ao trabalho de Musicalização:

Com crianças de 0 a 3 anos, o trabalho com Música deve estar organizado de forma que as crianças desenvolvam as seguintes capacidades:

a) Ouvir, perceber e discriminar eventos sonoros diversos, fontes sonoras e produções musicais;

b) Brincar com a música, imitar, inventar e reproduzir criações musicais.

Com crianças de 04 a 06 anos, todos os objetivos estabelecidos para a faixa etária de 0 a 03 anos deverão ser aprofundados e ampliados, garantindo-se ainda, oportunidades para que as crianças sejam capazes de:

a) Explorar e identificar elementos da música para se expressar, interagir com os outros e ampliar seu conhecimento de mundo;

b) Perceber e expressar sensações, sentimentos e pensamentos, por meio de improvisações, composições e interpretações musicais.

\section{PESQUISA DE CAMPO}


Ao longo de 10 anos de trabalho com educação musical, esta autora sempre se manteve atenta à forma subjetiva dos educandos se relacionarem com os conteúdos musicais. Em diversos momentos, sentiu necessidade de efetivamente comprovar se os benefícios da música poderiam ser observados no meio em que os educandos estavam inseridos e por pessoas que não tivessem necessariamente uma vivência musical. Isso por observar que os momentos de apresentações musicais e datas comemorativas ganhavam maior evidência do que o trabalho musical cotidiano, processo contínuo e muito importante para a formação de base, na opinião da autora.

Partindo dessas indagações, nasce a pesquisa em questão, realizada em um dos locais onde a autora trabalha. Trata-se de uma instituição privada, a qual atende, semanalmente, cerca de 100 educandos da Educação Infantil e do Ensino Fundamental I, ministrando aulas de Musicalização. Num período de 10 meses, observou-se os educandos e percebeu-se que demonstravam sensibilidade ao receber estímulos musicais, sobretudo os da Educação Infantil, participando com alegria, afetividade e atenção. A partir dessa percepção procurou-se estimulá-los, abrindo espaço para que mostrassem as músicas preferidas, expressando-se livremente, criando e ressignificando movimentos, jogos e brincadeiras musicais. O manuseio de instrumentos musicais também foi intensificado, e sempre ao mostrar a forma usual de tocar, proporcionava a experimentação mais livre, valorizando a criatividade e conhecimento prévio dos alunos.

No intuito de investigar contribuição das aulas de Musicalização na vivência dos educandos da Educação Infantil, potencializando seu desenvolvimento, a autora optou em obter depoimentos de professoras da Educação Infantil, pelo fato de as mesmas terem mais tempo de aula e convivência com os educandos. O instrumento escolhido para a coleta de informações foram questionários de caráter exploratório, com perguntas estruturadas a colher dados dos participantes, e a percepção das crianças após as aulas de musicalização e no cotidiano

Foram distribuídos 14 questionários à professoras de Educação Infantil, que deveriam ser respondidos no período de 23 a 30 de Novembro de 2018. Findo esse prazo, 10 professoras entregaram os questionários respondidos. As respostas foram identificadas, registradas e analisadas, e formam a base de dados da pesquisa descritiva qualitativa, que compõe essa seção. 


\section{SUJEITOS DA PESQUISA}

As participantes da pesquisa são 10 professoras regentes de turmas de Educação Infantil, que aqui terão seus nomes representados por abreviaturas. Todas trabalham na cidade de Barra Mansa, e são regentes de turmas cujos alunos participam das aulas de Musicalização.

Quanto às suas experiências profissionais, os dados são:

\section{Tempo que lecionam:}

- Menos de 01 ano: 02 professoras;

- Aproximadamente 02 anos: 06 professoras;

- Aproximadamente 04 anos: 01 professora

- Exatos 07 anos: 01 professora

\section{Experiência na rede pública e privada:}

- 09 professoras atuam somente em Escolas particulares;

- 01 professora atua também na rede pública;

Nos dados sobre o grau de escolaridade das pesquisadas contam:

- Ensino Superior (cursando): 04 professoras;

- Ensino Superior Completo: 06 professoras;

\section{ANALISE DOS QUESTIONÁRIOS}

As respostas obtidas nos questionários levaram-me aos seguintes apontamentos:

- 06 professoras declararam não ter nenhuma relação com Música e nenhuma prática Musical;

- 04 professoras se declararam apreciadoras de Música;

- Nenhuma se declarou instrumentista ou Musicista;

Numa análise geral dos questionários, é possível afirmar que todas as respostas às perguntas mostraram que a utilização da Música na Educação Infantil é "primordial para o desenvolvimento" dos educandos. A professora L.D. afirma que "A música na Educação Infantil possui um papel fundamental por contribuir com o desenvolvimento psicomotor, socioafetivo, cognitivo e linguístico, além de ser um facilitador no processo de aprendizagem.” A professora L.C. enfatiza que, além da importância da Música “[...] 
por meio dela são desenvolvidos ritmo e noção corporal, aspectos imprescindíveis nessa etapa."

Segundo as professoras, há poucos relatos de pais a respeito das aulas de Musicalização, mais precisamente 03 sinalizaram na pesquisa que os pais perguntaram sobre as aulas e comentaram que os filhos têm, nas residências, cantado mais, e querem ensinar os jogos musicais realizados em sala.

\section{A MUSICALIZAÇÃO NO COTIDIANO DOS ALUNOS DA EDUCAÇÃO INFANTIL}

Que o uso da Música é importante na Educação Infantil, foi opinião unânime entre as pesquisadas. Mesmo as professoras que afirmaram não ter nenhuma relação com Música e não se definiram nem como apreciadoras, julgam seu uso essencial. De acordo com as mesmas, o trabalho com Música na Unidade Escolar em que atuam acontece:

- Em aulas extracurriculares com a Professora de Música;

- Abordada por elas próprias, como trabalho coadjuvante em práticas e atividades cotidianas como: rodinha, organização da sala, chamadinha, entrar na fila, refeições, lavar as mãos ou escovar os dentes.

- Em Projetos, para ajudar na assimilação dos conteúdos.

Tais apontamentos evidenciam que na sala de aula a Música é utilizada como suporte para formação de hábitos e atitudes, às vezes em segundo plano. Segundo Jannibelli (1971, p. 35) professor [...] precisa alcançar uma compreensão exata do valor da música, na educação e na formação da personalidade dos educandos [...], e complementa que os professores desejosos em dirimir essa lacuna devem ser auxiliados e apoiados pelos professores especialistas e orientadores pedagógicos.

O RCNEI (BRASIL, 1998, p. 49) afirma que o trabalho musical deve estar integrado com outras áreas, porém "[...] é preciso cuidar, no entanto, para que não se deixe de lado o exercício das questões especificamente musicais."

\section{OS ALUNOS E A MUSICALIZAÇÃO: DESENVOLVIMENTO DE POTENCIALIDADES?}


Para Bréscia (apud CHIARELLI, 2005, p. 03) a musicalização favorece “[...] o desenvolvimento da sensibilidade, criatividade, senso rítmico, do prazer de ouvir música, da imaginação, memória, concentração, atenção, autodisciplina, do respeito ao próximo, da socialização e afetividade, também contribuindo para uma efetiva consciência corporal e de movimentação.” Para a professora I.R. o que mais chamou a atenção foi que "Os educandos se tornaram sensíveis e mais interativos com os demais alunos e funcionários. Os vínculos e emoções do conhecimento se tornaram mais presentes no meio familiar e social

$\mathrm{Na}$ opinião das 10 professoras, os educandos que têm aulas de Musicalização estão desenvolvendo de forma progressiva:

- Sensibilidade; interação; criação de vínculos; autoconhecimento; senso coletivo; disciplina; concentração; memorização; coordenação motora; oralidade e aquisição de vocabulário; ritmo; apreciação musical; noção temporal; afetividade; interesse; desinibição; socialização.

Dentre as habilidades citadas, que foram desenvolvidas na opinião das professoras pesquisadas, as diretamente relacionadas com a avaliação formativa realizada por professores, de acordo com o RCNEI (BRASIL, 1998, p.77), e que indicam aprendizagem musical de crianças de 0 a 06 anos são:

\begin{tabular}{|l|l|}
\hline $\begin{array}{l}\text { Potencialidades desenvolvidas - } \\
\text { educandos }\end{array}$ & Aprendizagem Musical de acordo com o \\
RCNEI
\end{tabular}


BORGES, S. M. N. A musicalização como ferramenta para o desenvolvimento de potencialidades na educação infantil. $R$. Cientifica UBM - Barra Mansa (RJ), ano XXIV, v. 21, n. 40, 1. Sem. 2019. p. 40-56.

ISSN 1516-4071

\begin{tabular}{|l|l|}
\hline desinibição; interação; & e ampliar seu conhecimento de mundo; \\
\hline Sensibilidade; autoconhecimento; & Perceber e expressar sensações, \\
oralidade e aquisição de vocabulário; ritmo; & sentimentos e pensamentos, por meio de \\
& improvisações, composições e \\
& interpretações musicais. \\
\hline
\end{tabular}

O RCNEI (BRASIL, 1998, p. 77) orienta que “A avaliação na área de música deve ser contínua, levando em consideração os processos vivenciados pelas crianças, resultado de um trabalho intencional do professor.” Baseada na observação cuidadosa do professor, deve ser instrumento para a reorganização de objetivos, conteúdos, procedimentos, atividades, e como forma de acompanhar e conhecer cada criança e grupo. O mesmo documento ainda sugere propiciar os educandos uma autoavaliação, gravando em áudio suas produções, para que possam ouvir e perceber como foi produção vocal, volume dos instrumentos, sons utilizados e etc.

\section{Considerações Finais}

Por percebermos que a Música pode contribuir para o desenvolvimento pessoal dos indivíduos, optamos por levar o foco da pesquisa para a musicalização, uma vez que oportuniza pesquisar e escrever sobre questões que por vezes vivenciamos em nosso cotidiano.

A inserção dentro dessa temática traz a possibilidade de rever práticas, pois as informações colhidas trazem à tona pontos positivos e pontos que podem ser potencializados, através de reflexão, reavaliação e consulta à material especializado, como se deu com a autora. Não buscamos generalizar as experiências, mas acreditamos que a pesquisa possa modestamente contribuir para que outros professores redirecionem o uso da Música em sala de aula, ampliando seu papel atual de coadjuvante em rotinas, para o de ferramenta potente que contribui para o desenvolvimento.

Relacionar a percepção das potencialidades colhidas na pesquisa com o RCNEI é importante para que o trabalho de Música não fique “solto", atendendo à 
regulamentação nacional do trabalho de Música com crianças de 0 a 06 anos, dentro do espaço em que ele é realizado (escolas e creches).

Em nossa experiência de docência, tanto na área da Educação quanto da Música, encontramos profissionais da área que ainda desconhecem o RCNEI. Jannibelli (1971, p. 35) afirma que entre as obrigações docentes do professor está a de [...] desenvolver de maneira harmoniosa todas as capacidades de seus alunos [...] e explica que para esse fim o professor tem que lançar mão de vários recursos, entre eles a Música. Ter professoras identificando o desenvolvimento de potencialidades reforça e consolida a importância de um trabalho de Música nas turmas de Educação Infantil, pois várias das potencialidades citadas pelas pesquisadas são objetivos pelos quais o trabalho de Musicalização se fundamenta. As professoras também observaram que os educandos voltam das aulas de Musicalização mais "alegres" e "tranquilos". Alguns autores citados neste trabalho afirmam que essa volta calma é primordial, pois a abordagem lúdica e prazerosa traz significado ao aprendizado.

$\mathrm{O}$ fato de as habilidades desenvolvidas pelos educandos estarem relacionadas às experiências prioritárias que denotam aprendizagem citadas no RCNEI, legitimam e consolidam a Musicalização como essencial no desenvolvimento de potencialidades dos alunos da Educação Infantil.

Observou-se, ao longo desta pesquisa, que a música nas unidades escolares muitas vezes tem papel secundário; atende à formação de hábitos e atitudes; como suporte em projetos; destinada a apresentações do calendário escolar. Brito (2003, p. 52) alerta que o caráter de espetáculo que frequentemente ronda o trabalho musical pode ser um complicador, pois se dedica muito tempo a ensaios e apresentações em comemorações. Segundo o RCNEI (BRASIL, 1998, p. 47) há grande dificuldade em integrar a linguagem musical ao contexto educacional.

Por fim, concluímos que a musicalização contribui para o desenvolvimento dos educandos da Educação Infantil ao estimular suas potencialidades e servir de ponte para que estreitem sua relação com a Música. Observar a forma como a Música atua na vida dos indivíduos é fonte de inspiração, que agrega maior sentido na caminhada como docente. 
BORGES, S. M. N. A musicalização como ferramenta para o desenvolvimento de potencialidades na educação infantil. $R$. Cientifica UBM - Barra Mansa (RJ), ano XXIV, v. 21, n. 40, 1. Sem. 2019. p. 40-56.

ISSN 1516-4071

\section{Referências}

BRASIL. Ministério da Educação e do Desporto, Secretaria de Educação Fundamental. Referencial Curricular Nacional para a Educação Infantil. Brasília: MEC/SEF, 1998. 3v.:il.

BRÉSCIA, Vera Lúcia Pessagno. Educação Musical: Bases psicológicas e ação preventiva. São Paulo: Átomo, 2003.

BRITO, Teca Alencar de. Música na Educação Infantil. São Paulo: Peirópolis, 2003.

CAGE, J. De segunda a um ano. Trad. Rogério Duprat. São Paulo: Hucitec, 1985.

CARDOSO, Belmira e MASCARENHAS, Mário. Curso completo de teoria musical e solfejo. São Paulo: Irmãos Vitale, 1973.

CHIARELLI, Lígia Karina Meneghetti. A importância da musicalização na Educação Infantil e no Ensino Fundamental: a música como meio de desenvolver a inteligência e a integração do ser. Disponível em:

http://www.iacat.com/revista/recrearte/recrearte03/musicoterapia.htm

Acessado em: 20/08/18

HOUAISS, A. e VILLAR, M. de Salles. Dicionário Houaiss da Língua Portuguesa. Rio de Janeiro: Objetiva, 2001.

JANNIBELLI, Emília D’Anniballe - A Musicalização na Escola. Rio de Janeiro: Lidador, 1971.

KISHIMOTO, Tizuko Morchida; SANTOS, Maria Walburga dos. Educação Infantil em São Paulo entre 1920 e 1940: um estudo de caso sobre Alice Meireles Reis. In: VI Congresso Luso Brasileiro de História da Educação - Colubhe 06, 2006, Uberlândia Disponível em: D:\arquivos\58TizukoMorchidaKishimoto_MariaWalburgaSantos.pdf 2006. Acesso em: 29/06/18.

PENNA, Maura L. Reavaliações e buscas em Musicalização. São Paulo: Edições Loyola, 1990. 
BORGES, S. M. N. A musicalização como ferramenta para o desenvolvimento de potencialidades na educação infantil. $R$. Cientifica UBM - Barra Mansa (RJ), ano XXIV, v. 21, n. 40, 1. Sem. 2019. p. 40-56.

ISSN 1516-4071

SOUZA, Jusamara. Educação musical e práticas sociais. Experiências com Sons, Ritmos, Música e Movimento na Pré-Escola. Porto Alegre: Kuarup, 2004. 